\title{
A brief review on Triazin-pyridazinones: Synthesis and biological activities
}

\author{
M.Asif* \\ Department of Pharmacy, GRD (P.G) Institute of Management and Technology ,Dehradun, (Uttarakhand), \\ 248009, India
}

ARTICLE INFO: Received: 29 Aug, 2016; Revised: 23 Nov, 2016; Accepted: 30 Nov, 2016

\begin{abstract}
A series of substituted triazin-pyridazine compounds were exhibited diverse types of biological activities and synthesized by different methods. These compounds were mainly tested for their anti-inflammatory, anticancer, antifungal and antibacterial activities. These substituted triazin-pyridazine compounds have mild to potent activities on compare with their appropriate reference standards.
\end{abstract}

Keywords: Triazolo-pyridazinones, Cytotoxicity, Pyridazin,antifungal, antibacterial, triazole

Copyright $\odot 2016$ Asif M. This is an open access article distributed under the Creative Commons Attribution 4.0 International License CC BY, which permits unrestricted use, distribution, and reproduction in any medium, provided the original work is properly cited.

\section{INTRODUCTION}

Heterocyclic annelated pyridazines attract considerable attention, which mainly arises from the large variety of interesting pharmacological activities observed with pyridazine derivatives [1-6]. In recent years, synthesis of novel pyridazinone derivatives and investigation of their chemical and biological behavior have gained more importance due to their biological, medicinal, and agricultural reason. This privileged structure attracts the interest of medicinal chemists as a nucleus of potential therapeutic utility and exhibits several pharmacological activities such as analgesic, anti-inflammatory, antidepressant, antihypertensive, anticonvulsant, cardiotonic, diuretic, anticancer, and anti-HIV activities [7-12]. In addition, pyridazinones act as core nucleus in various drugs e.g. Sul-mazole, Amipizone, Indolidan, Levosimendan, Imazodan, Pimobendan, Emorfazone, Zardaverine and Milrinone [13-15]. Triazole and its derivatives are noteworthy for their physiological and biological importance. They paved the attention of medicinal chemist due to their wide range of biological activities like anti-inflammatory, antiviral, antifungal, antibacterial, anticonvulsant and anticancerousetc [16-20]. Triazolopyridazine derivatives are frequently used in biological research [21,22].

Anti inflammatory and analgesic activity: Non-steroidal anti-inflammatory drugs (NSAIDs) are the most commonly prescribed medications for the treatment and/or management of pain, fever, and inflammation. However, their long term use is linked with gastroenteropathy such as gastric irritation, ulceration, bleeding and renal toxicity that limit their therapeutic usefulness [23]. Therefore, the synthesis of new compounds devoid of such side effects poses a challenging task for medicinal chemists. The currently used NSAIDs inhibit the synthesis of non

*corresponding author: e-mail: aasif321@gmail.com DOI: http://dx.doi.org/10.5564/mjc.v17i43.743 selective or selective cyclooxygenases (COX1 \& COX2 or prostaglandin, histamine and bradykinin [24-26]. It has been suggested that prostaglandins and bradykinins play a major role in the analgesia or pain. So it may be pre dicted that the title compounds may act by inhibiting the synthesis of these chemical mediators involved in causing pain as well as inflammation [27]. The pyridazinones having characteristic pharmacological features, relative stability and ease of preparation contemplated us to synthesize some new derivatives of pyridazinones as good analgesic and anti-inflammatory agents. Various substituted pyridazinone derivatives possessing analgesic activity along with other useful pharmacological properties have been reported. Emorfazone (4-ethoxy-2-methyl-5-morpholino$3(2 \mathrm{H})$-pyridazinone) is a pyridazinone derivative which is currently used clinically in the management of pain and inflammation. Antinociceptive activity of 4-amino-2-methyl-6-phenyl-5-vinyl-3(2H)-pyridazinonewhich was found to be many fold potent than the emorfazone. A series of 2/3-substituted-6(4-methylphenyl)-4,5-dihydro-pyridazin3(2H)-ones and Pyridazine substituted Triazine were developed that allow efficient preparation of analogues with varied substitutions on the pyridazinone ring [28]. Somepyridazine derivatives were evaluation of their analgesic and anti-inflammatory activities to obtainesafer non-steroidal anti-inflammatory agents (NSAIDs). The aryl propionic acid on reaction with phenyl hydrazine and hydrazine hydrate yielded the pyridazinone derivative, 6-(4-Methylphenyl)-2-phenylpyridazin-3(2H)-one (1) and 6-(4-Methylphenyl)-4,5-dihydropyridazin-3(2H)-one (2), respectively. The reaction of the compound 2 with phosphorus oxychloride $\left(\mathrm{POCl}_{3}\right)$ produced the corresponding chloropyridazine derivative, 3-Chloro-6-(4-methylphenyl)-pyridazine (3). A 2-(Hydroxymethyl)-6-(4-methylphenyl)-4,5-dihydropyridazin-3(2H)-one (4)was synthesized by condensing 2 with methanol and formaldehyde $(\mathrm{HCHO})$. The compound 4 on further treatment with 
guanidine hydrochloride in ethanol gave the pyridazino-triazine, 7-(4-methylphenyl)-3,4,8,9-tetrahydro-2H-pyridazino[1,6-á][1,3,5]triazin-2-imine (5). The compounds were tested for their analgesic activity in mice and anti-inflammatory activity in Wistar albino rats. The results of in-vivo anti-inflammatory studies revealed that the compound $\mathbf{3}$ showed maximum inhibition in paw edema volume followed by compound 2 while the compound $\mathbf{3}$ exhibited excellent peripheral analgesic activity (74\%) followed of the compound $\mathbf{4}$. Compounds $\mathbf{3}$ and $\mathbf{4}$ also showed a good central analgesic effect increased the reaction time to 90 minutes [28].<smiles>Cc1ccc(C2CC(=O)N(CO)N=C2N2N=C(Cl)CCN2N=C2CC(=O)N(CO)N=C2c2cc(C3=NN(c4ccccc4)C(=O)CC3)ccc2C)cc1</smiles>

Compounds, 2 and $\mathbf{3}$, had smaller paw volume than the positive control and were found to be more potent. All the tested compounds except compound 4 exhibited the maximum reduction in paw volume at 120 min while 4 displayed the maximum protection at $90 \mathrm{~min}$. It could be concluded that the anti-inflammatory activity of the synthesized compounds could be due to the inhibition of inflammatory mediators release and possibly due to the inhibition of COX synthesis similar to indomethacin. It was observed that substitution of 2-phenyl ring at p-position with $-\mathrm{CH}_{2} \mathrm{OH}$ in compound 4 decreases the anti-inflammatory activity. However, the best activity is shown by compound (2) having no substituent at second position of pyridazine ring. Further, replacing an oxo group at third position with a -chloro group does not lead to change in the activity. Compound (3) was found to be the most potent analgesic agent with respect to standard drug. Other compounds also showed moderate to good analgesic activity. The results indicated that pyridazine derivatives possess significant analgesic activity associated with NSAIDs properties. All title compounds exhibited anti-inflammatory activity that lasted for $90 \mathrm{~min}$ and the potency increased with time. Among the synthesized pyridazinones, compound 3 emerged as lead compound with good analgesic and anti-inflammatory activities at par with the reference drug. Most of the compounds were exhibited and analgesic effect by both peripheral and central mechanisms. The anti-inflammatory and analgesic potential of $2 / 3$ substituted pyridazine derivatives was confirmed. However, further detailed investigations are needed to establish the safety, efficacy and mechanism of this promising class of heterocyclic compounds [28]. Antimicrobial activity: A series of 3-substituted phenyl-6-substituted phenyl $(1,2,4)$ triazolo(4,3-b) pyridazine has been synthesized. The corresponding aroyl propionic acid was cyclised with hydrazine hydrate to give 6-(substituted aryl)-2,3,4,5-tetrahydro-3-pyridazinone, which was heated on steam bath with phosphorous oxy chloride to yield 3-chloro-6-substituted phenyl pyridazine. This intermediate after reaction with hydrazine hydrate was converted into 3-hydrazino-6-substituted phenyl pyradazine. The resulting product was converted into 3 -substituted phenyl 6 -substituted phenyl(1,2,4)triazolo(4,3-b)pyridazine by reacting with substituted aroyl chloride. The synthesized compounds were investigated for their in vitro antifungal and antibacterial activities. The results indicated that the synthesized compounds have mild to potent activities with reference to their appropriate reference standards [29]. The synthesized 3-phenyl 6-(4'-tolyl) $(1,2,4)$ triazolo $(4,3-$ b) pyridazine (6a), 3,6-di(4'-tolyl) (1,2,4)triazolo(4,3-b) pyridazine (6b), 3-phenyl 6-(2',4'-dimethyl phenyl)(1,2,4) triazolo(4,3-b) pyridazine (7a), 3-(4'-tolyl)-6-(2',4'-dimethyl phenyl)(1,2,4) triazolo(4,3-b)pyridazine (7b), 3-phenyl6-(4'-phenoxyphenyl)(1,2,4)triazolo(4,3-b)pyridazine (8a).3-(4'-tolyl)-6-(4'-phenoxyphenyl)(1,2,4)triazolo(4,3-b) pyridazine (8b), 3-phenyl 6-(4'-chloro phenyl)(1,2,4) triazolo(4,3-b)pyridazine (9a), 3-(4'-tolyl)-6-(4'-chloro phenyl)(1,2,4) triazolo(4,3-b) pyridazine (9b), 3-phenyl-6(4'-bromo phenyl)(1,2,4)triazolo(4,3-b)pyridazine (10a) and 3-(4'-tolyl)-6-(4'-bromo phenyl)(1,2,4)triazolo (4,3-b) pyridazine (10b) compounds were evaluated for their antibacterial activity against EscherichiaColi, Staphylococcus aureus, Micrococcus luteus and Klebsiella pneumonia. The results of antibacterial exhibit that all compounds having comparable activity against the bacterial strain. Compounds $\mathbf{6 b}, \mathbf{7 b}$ and $\mathbf{8 b}$ are the most active derivatives, which shows significant activity against these bacteria comparable to standard drug, ampicillin and chloramphenicol. All the final compounds were evaluated for antifungal activity against Candidaalbicans and Candidaneoformans and compared with standard drug fluconazole. The compounds $\mathbf{7 a}, \mathbf{7 b}$ and $\mathbf{9 b}$ were found to be active derivatives of this series against the microorganism. It is concluded that compounds $\mathbf{6 b}, \mathbf{7 b}$ and $\mathbf{8 b}$ are active against gram positive and gram negative bacteria. Compound $\mathbf{7 a}, \mathbf{7 b}$ and $\mathbf{9 b}$ are potent antifungal drugs [29]. The 6-substituted phenyl-2-[\{(4'-substituted phenyl5'-thioxo)-1,2,4-triazol-3-yl\}-methyl]-2, 3, 4, 5tetrahydropyridazin-3-one (11-20) compounds were tested for their in vitro antifungal activity on five fungal species, namely Candida albicans, Trichophyton rubrum, Aspergillus flavus, Aspergillus niger and Penicillium citrinium. The antifungal activities of the 6-Substituted-2-\{[(4'substituted-phenyl-5íthioxo)-1,2,4-triazol-3-yl]-methyl]2,3,4,5-tetrahydropyridazin-3-one compounds (11-20) against different Candida albicans, Trichophyton rubrum, Aspergillus flavus, Aspergillus niger and Penicillium citrinium fungal species and the results were compared with the standard drug voriconazole. The MIC of voriconazole for all the fungal species was lower than $0.5 \mu \mathrm{g} / \mathrm{mL}$. All compounds were found significant antifungal activities against all the fungal species. The chloro substituent derivative (17) showed the highest activity against all the fungal species. The MIC of the voriconazole was between 0.10 and $0.50 \mu \mathrm{g} / \mathrm{ml}$ against all the fungal species. The two electronegative groups of $\mathrm{Cl}$ was increasing the activity of 1,2,4-triazole.The bulky group or aromatic group on benzene ring decreased the activity.

Anticancer activity: The triazolo[4,3-b]pyridazinones were evaluated for their potential in vitro cytotoxic 
<smiles>Cc1ccc(-c2ccc3nnc(-c4ccccc4)n3n2)cc1</smiles>

(6a)<smiles>Cc1ccc(-c2ccc3nnc(-c4ccc(C)cc4)n3n2)cc1</smiles>

(6b)<smiles>Cc1ccc(-c2cc(-c3ccccc3)c3nncn3n2)c(C)c1</smiles>

(7a)<smiles>Cc1ccc(-c2nnc3ccc(-c4ccc(C)cc4C)nn23)cc1</smiles>

(7b)<smiles></smiles>

(8a)<smiles>C/C=C\c1nnc2ccc(-c3ccc(Oc4ccccc4)cc3)nn12</smiles>

(10b)

(10b)<smiles>Clc1ccc(-c2ccc3nnc(-c4ccccc4)n3n2)cc1</smiles>

(9a)<smiles>Cc1ccc(-c2nnc3ccc(-c4ccc(Cl)cc4)nn23)cc1</smiles>

(9b)<smiles>Brc1ccc(-c2ccc3nnc(-c4ccccc4)n3n2)cc1</smiles>

(10a)<smiles>O=C1CCC(c2ccccc2)=NN1Cc1n[nH]c(=S)n1-c1ccccc1</smiles>

(11)<smiles>O=C1CCC(c2ccccc2)=NN1Cc1n[nH]c(=S)n1-c1ccc(Cl)cc1</smiles>

(12)<smiles>O=C1CCC(c2ccccc2)=NN1Cc1n[nH]c(=S)n1-c1ccc(Br)cc1</smiles>

(13)<smiles>Cc1ccccc1C1CC=NN(Cc2n[nH]c(=S)n2-c2ccccc2)C1=O</smiles>

(14)<smiles>Cc1ccccc1C1CC=NN(Cc2n[nH]c(=S)n2-c2ccc(Cl)cc2)C1=O</smiles>

(15)<smiles>Cc1ccccc1C1CC=NN(Cc2n[nH]c(=S)n2-c2ccc(Br)cc2)C1=O</smiles>

(16)<smiles>O=C1C(c2ccccc2Cl)CCNN1Cc1n[nH]c(=S)n1-c1ccc(Cl)cc1</smiles>

(17)<smiles>O=C1C(c2ccccc2Br)CC=NN1Cc1n[nH]c(=S)n1-c1ccc(Cl)cc1</smiles>

(20)<smiles></smiles>

(18)<smiles>O=C1C(c2ccccc2Br)CC=NN1Cc1n[nH]c(=S)n1-c1ccccc1</smiles>

(19)<smiles>CCOC(=O)C1=NN(c2ccc(Cl)cc2)C2(C)CCC(=O)NN12</smiles>

(21)<smiles>CCOC(=O)C1=NN(c2ccc([N+](=O)[O-])cc2)C2(C)CCC(=O)NN12</smiles>

(22)<smiles>CCOC(=O)C1=NN(c2ccc(C)cc2)C2(C)CCC(=O)NN12</smiles>

(23)<smiles>CCOC(=O)C1=NN(c2ccc(OC)cc2)C2(C)CCC(=O)NN12</smiles>

(24) antitumor properties. The compounds were prepared by 1,3-dipolar cyclo addition of pyridazin-3-ones with $\mathrm{N}$-aryl-C-ethoxycarbonylnitrile imines, generated in situ from ethylhydrazono-a-bromoglyoxylates.

The triazolo[4,3-b]pyridazinones (21-27) have been synthesized with the aim to evaluate their cytotoxic activity against tumor cells. Cells $(105 / \mathrm{ml})$ were treated with increasing concentrations of compounds 22-24, followed by $48 \mathrm{~h}$ incubation. In vitro evaluation of the cytotoxic effect of compounds $\mathbf{2 3}$ and $\mathbf{2 4}$ showed that both of these 
<smiles>CCOC(=O)C1=NN(c2ccc(Cl)cc2)C2(c3ccccc3)CCC(=O)NN12</smiles>

(25)<smiles>CCOC(=O)C1=NN(c2ccc([N+](=O)[O-])cc2)C2(c3ccccc3)CCC(=O)NN12</smiles>

(26)<smiles>CCOC(=O)C1=NN(c2ccc(C)cc2)C2(c3ccccc3)CCC(=O)NN12</smiles>

(27)<smiles>CCOC(=O)C(Nc1ccccc1)c1nnc2ccc(Cl)nn12</smiles>

Scheme 1. Synthesis of 2-amino-2-(6-chloro-[1,2,4]triazolo[4,3-b]pyridazin-3-yl) acetic acid from ethyl 2-(benzamido)-2-(6-chloro-[1,2,4]triazolo[4,3-b]pyridazin-3-yl) acetate.

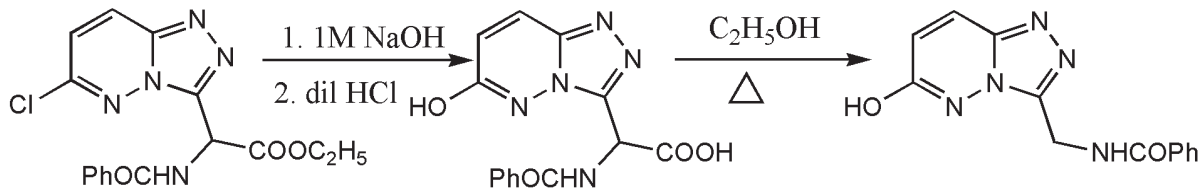

I

III

IV

Scheme 2. Synthesis of 2-amino-2-(6-chloro-[1,2,4]triazolo[4,3-b]pyridazin-3-yl) acetic acid and N-((6-hydroxy-[1,2,4] triazolo[4,3-b]pyridazin-3-yl)methyl) benzamide from ethyl 2-(benzamido)-2-(6-chloro-[1,2,4]triazolo[4,3-b]pyridazin-3-yl) acetate.
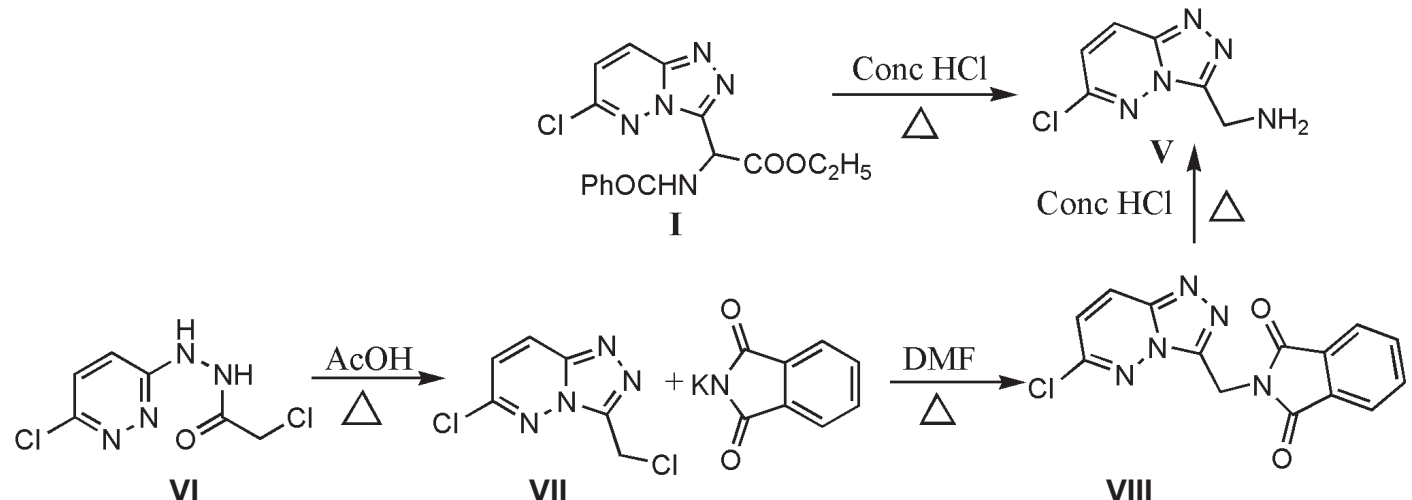

Scheme 3. Synthesis of 2-((6-chloro-[1,2,4]triazolo[4,3-b]pyridazin-3-yl)methyl) isoindoline-1,3-dione and (6-chloro-[1,2,4]triazolo[4,3-b]pyridazin-3-yl) methanamine

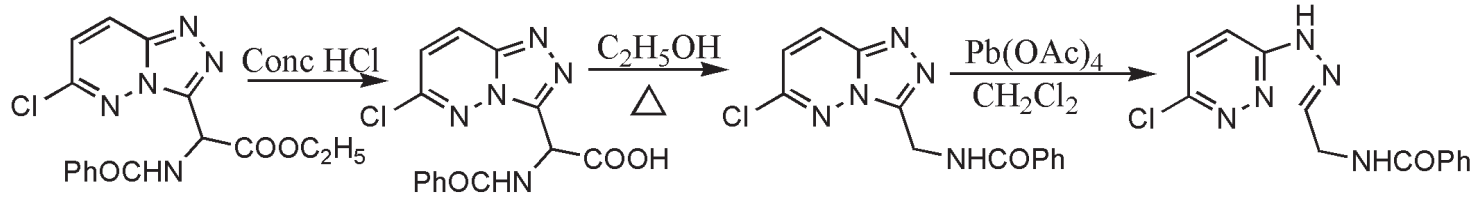

$\mathrm{IX}$

$\mathbf{X}$

$\mathbf{X I}$

Scheme 4. Synthesis of 2-(benzamido)-2-(6-chloro-[1,2,4]triazolo[4,3-b]pyridazin-3-yl) acetic acid, N-((6-chloro-[1,2,4] triazolo[4,3-b]pyridazin-3-yl)methyl) benzamide and compound (XI) from ethyl 2-(benzamido)-2-(6-chloro-[1,2,4]triazolo[4,3-b]pyridazin-3-yl) acetate (I).

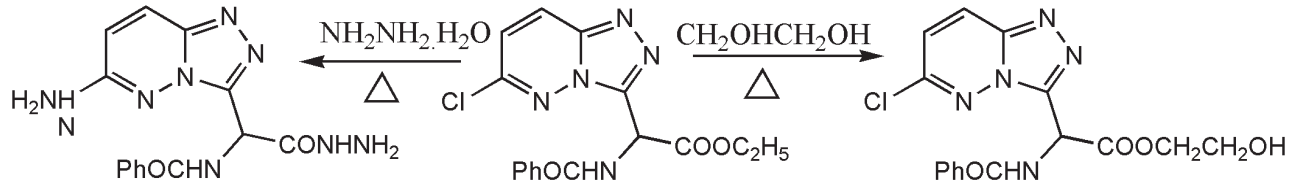

XII 
products are cytotoxic to the HepA cell line in a dosedependent manner, with $\mathrm{IC}_{50}$ values of $20.76 \mu \mathrm{g} \mathrm{ml}-1$ and $9.2 \mu \mathrm{g} \mathrm{ml}-1$, respectively. It is noteworthy that the cytotoxic effect of these products is weaker than that induced by adriamycin $\left(\mathrm{IC}_{50}: 1.2 \mu \mathrm{g} \mathrm{ml}-1\right)$. The compound 24 was more cytotoxic than compound 23. Compound 24 exhibited significant cytotoxicity against the Hep cell line [31].

Synthesis: The preparation of some derivatives of the $[1,2,4]$ triazolo[4,3-b]pyridazine system from ethyl N-benzoyl-(6-chloro[1,2,4]triazolo[4,3-b]pyridazin-3yl)glycinate is reported [32]. A general approach to ethyl $N$-benzoyl-a-hetero-aryl-glycinates based on the annulation of the 1,2,4-triazole ring on the suitably substituted azine or fused azine derivative (Scheme 1). The $[1,2,4]$ triazolo[4,3- $b]$ pyridazine system has attracted great attention, it explore synthetic utility of compound I in the preparation of some other derivatives. In particular, interest in the preparation of the amino acid II [21].

Reaction of I with hot $1 \mathrm{M}$ sodium hydroxide solution took place on the ethoxycarbonyl group and at the position 6 of the triazolopyridazine system to give III, which underwent decarboxylation in hot ethanol affording benzamide IV (Scheme 2) [21].

Refluxing of I in diluted hydrochloric acid (1:1) for 4 h gave hydrochloride $\mathbf{V}$. This compound was also prepared via a longer reaction sequence starting from hydrazide VI which was firstly transformed by heating in acetic acid into the chloromethyl substituted triazolopyridazine VII. Substitution of the chloro group with potassium phthalimide in hot N,N-dimethylformamide produced VIII, which hydrolyzed in hot hydrochloric acid to give V (Scheme 3). On the other hand, treatment of I with concentrated hydrochloric acid at room temperature for 15 days yielded acid IX, which similarly as III underwent decarboxylation by heating in ethanol giving benzamide $\mathbf{X}$. The latter was also prepared by oxidative cyclization of hydrazone XI [34]. Evidently, strong reaction conditions required for the elimination of the protective groups caused the decarboxylation of IX making impossible the preparation of the acid II (Scheme 4).

Stable triazolopyridazine were obtained in reactions of 1 with hydrazine hydrate and ethylene glycol. Reaction with hot $80 \%$ hydrazine hydrate proceeded similarly as with sodium hydroxide at two electron deficient carbons, carbon 6 and carbonyl group, giving hydrazide XII, whereas treatment with hot ethylene glycol resulted in the formation of XIII. Both products might be suitable starting compounds for the preparation of some tricyclic systems, the former also for the peptide synthesis (Scheme 5).

\section{CONCLUSION}

Pyridazine is an important heterocyclic scaffold for designing medicinal agents with varying biological actions. The easy functionalization at various ring positions makes them an attractive synthetic building block for designing, synthesis and discovery of new drugs. The incorporation of this versatile biologically accepted pharmacophore in established medicinally active molecules results in wide range of pharmacological effects. Further optimization of the chemical synthesis can possibly lead to more active molecules against fungal infections. Since all twelve compounds showed promising results, studies to establish their in vivo efficacy will be carried in the future.

\section{REFERENCES}

1. Mátyus P., Maes B.U.W., Riedl Z., Hajós G., Lemière G.L.F., et al. (2004) New Pathways Towards Pyridazino-Fused Ring Systems. Synlett.,1123.

2. Lee S.G., Kim J.J., Kim H.K., Kweon D.H., Kang Y.J., et al. (2004) Recent progress in pyridazin-3(2h)-ones chemistry. Curr. Org. Chem., 8, 1463.

3. Eric A. Meade, Linda L. Wotring, John C. Drach, Leroy B. (1993) Townsend Synthesis, antiproliferative, and antiviral activity of 4-amino-1-(.beta.-D-ribofuranosyl) pyrrolo[2,3-d]pyridazin-7(6H)-one and related derivatives J. Med. Chem., 36(24), 3834-3842.

4. Meade E.A, Wotring L.L, Drach J.C, Townsend L.B. (1997) Synthesis and antiproliferative and antiviral activity of carbohydrate-modified pyrrolo[2,3-d] pyridazin-7-one nucleosides. J. Med. Chem., 40(5), 794-801.

5. Ostby O.B., Gundersen L-L., Rise F., Antonsen O., Fosnes K., et al. (2001) Synthesis of 5-Substituted Pyrrolo[1,2-b]pyridazines with Antioxidant Properties. Arch. Pharm. Pharm. Arch. Pharm. Pharm. Med. Chem., 334, 21.

6. Byth K.F., Cooper N., Culshaw J.D., Heaton D.W., Oakes S.E., et al. (2004) ) Imidazo[1,2-b]pyridazines: a potent and selective class of cyclin-dependent kinase inhibitors. Bioorg, Med. Chem. Lett., 14, 2249.

7. Asif M., Singh A. (2013) Analgesic and antiinflammatory activities of several 4-substituted-6(3'-nitrophenyl)pyridazin-(2H)-3-one derivatives. Brazilian. J. Pharm. Sci., 49(4), 903-909.

8. Asif M, Singh A, Ratnakar. (2011)Antimicrobial Agents: Brief Study of Pyridazine Derivatives against Some Phathogenic Microrganisms.J.Pharm.Res., 4,664-667.

9. Asif M. (2014) A Review on Study of Various Ionotropic Calcium Sensitizing Drugs in Congestive Heart Failure Treatment. Am. J. Med. Case. Rep., 2(3), 57-74.

10. Asif M, Singh A, Lakshmayya. (2013) Development of structurally diverse antitubercular molecules with pyridazine ring. Chronicles of Young Scientists, 4(1)1-8.

11. Asif M. (2015) 1,2-Diazines and Annulated Derivatives In Methods Of Organic Chemistry (Houben-Weyl) Open J Biomed Mat Res., 2(1), 1-6.

12. Asif M., Singh A. (2010) Exploring Potential, Synthetic Methods and General Chemistry of Pyridazine and Pyridazinone: A Brief Introduction. Inter. J. Chem Tech Res., 2(2), 1112-1128.

13. Asif M. (2013) Recent Approaches toward Anticonvulsant Activity of Pyridazine Compounds. J Org. Chem., 1(2),11-21.

14. Asif M. (2012) Some RecentApproaches of Biologically Active Substituted Pyridazine and Phthalazine Drugs. Curr. Med. Chem., 19(18), 2984-2991.

15. Asif M., Singh A., Siddiqui A.A. (2012) The effect of pyridazine compounds on the cardiovascular system. Med. Chem. Res, 21, 3336-3346.

16. Amir M., Kumar S. (2004) Synthesis of some new 2, 5-disubstituted 1, 3, 4-oxadiazole derivatives and their anti inflammatory activity, Ind. J. Het. Chem., 14, 51-54. 
17. Bhat M., Khan S.A., Siddiqui N. (2005) Synthesis and Antibacterial activity of coumarin incorporated 1,3,4-oxadiazoles. Ind. J. Het. Chem., 14, 271.

18. Khan M.S.Y., Drabu S. (2001) Anticonvulsant and antibacterial activity of some new 1, 3, 4-oxadiazole derivatives. Ind. J. Het. Chem., 11, 119.

19. Nizamuddin., Mishra M., Srivastva MK. (2001) Synthesis and fungicidal activity of 3,6,9-triaryl2-thioxothiazolo[4,S-d]-[1,3,4]oxadiazolo[2,3-b] pyrimidine and 3, IO-diaryl-2-thioxothiazolo[ 4,S-d]pyrimido [2, I-b] pyrimidines. Ind. J Chem., 40B, 49.

20. Jantova S., Letasiova S., Ovadekova R., Muckoa M. (2006) Cytotoxic/antiproliferative effects of new $[1,2,4]$ triazolo[4,3-c] quinazolines in tumor cell lines HeLa and B16. Neoplasm, 53(4), 291.

21. Hajós G., (1996) in: Katritzky A.R, Rees C.W., Scriven E.F.V., (Eds.), Comprehensive Heterocyclic Chemistry II, Pergamon Press, Oxford, 8, 417.

22. Abouricha S., Rakib E.M., Benchat N., Alaoui M., Allouchi H., et al. (2005) Facile synthesis of new spirothiadiazolopyridazines by 1,3-dipolar cycloaddition. Synth. Commun., 35, 2213.

23. Abouzid KAM., Khalil NA., Ahmed EM.Med. (2012) Design, synthesis, and evaluation of anti-inflammatory and ulcerogenicity of novel pyridazinone derivatives. Chem. Res., 21, 3581-3590.

24. Dogruer D.S., Sahin M.F., Kupeli E., Yesilada E. (2003) Synthesis and Analgesic and Antilnflammatory Activity of New Pyridazinones. Turk. J. Chem., 27, 727-738.

25. Sahina MF., Badicoglu B., Gokce M., Kupeli E., Yesilada E. (2004) Synthesis and analgesic and antiinflammatory activity of methyl 6-substituted3(2h)-pyridazinone-2-ylacetate derivatives. Arch. Pharm(Weinheim)., 337(8), 445-452.

26. Tazkoparan B., Gokhan N, Aktay G, Yesilada E., Ertan M. (2000) 6-benzylidenethiazolo [3, 2-b]-1, 2, 4-triazole-5 (6h)-onessubstituted with ibuprofen: Synthesis, characterizationand evaluation of antiinflammatory activity. Eur. J. Med. Chem., 34, 743-750.
27. McCarthy D. (1998) Nonsteroidal anti-inflammatory drug-related gastrointestinal toxicity: definitions and epidemiology. Am. J. Med., 105, 3S-9S.

28. Khokra S.L., Seth S., Garg S.S., Kaushik P., Ahmad A. (2015) Synthesis, computer aided screening and pharmacological evaluation of 2/3-substituted-6(4methylphenyl)-4,5-dihydropyridazin3(2h)-ones, and pyridazine substituted triazine. Indonesian J. Pharm., 26(4), 200-209.

29. Islam M., Aljaiyash A.A.H. (2013) Synthesis, antifungal, and antibacterial activities of 3-substituted phenyl-6substitutedphenyl-(1,2,4)-triazolo-(4,3-b)-pyridazines. Der Pharm Lett., 5(5), 27-34.

30. Siddiqui A.A., Ahamad S.R., Mir M.S., Hussain S.A., Raish M., Kaur R. (2008) Synthesis and invitro antifungal activity of 6-substituted-phenyl-2$\left\{\left[\left(4^{\prime}\right.\right.\right.$-substituted phenyl-5'-thioxo)-1,2,4-triazol3-yl]-methyl\}-2,3,4,5-tetrahydropyridazin-3-one derivatives. Acta Pol Pharm-Drug Res, 65(2), 223-228.

31. Rakib E.M., Abourich S., Hannioui A., Benchat N., Ait M'barek L., et al. (2006) Synthesis and in vitro cytotoxicity studies of novel triazolo [4, 3-b] pyridazinones. J. Iran Chem. Soc., 3(3), 272-276.

32. Cucek K., Verček B. (2001) Synthesis of novel $[1,2,4]$ triazolo[4,3-b]pyridazines. Arkivoc, 79-86.

33. Čuček K., Verček B. (1994) A Novel Approach to Heterocyclic Amino Acid Derivatives. Synthesis of Some Racemic Ethyl N-Benzoyl-aheteroarylglycinates Containing Fused 1,2,4-Triazole Systems. Synlett, 8, 667.

34. Čuček K., Mušič I., Verček B. (1996) A Convenient Synthesis of $\mathrm{N}$-[2-(Heteroarylhydrazono) Ethyl] Benzamides. Synth. Commun., 26, 1135. 